\title{
7. Collaboration in development between U.S. foundations and African universities
}

\section{Fabrice Jaumont and Teboho Moja}

\section{INTRODUCTION}

The development of higher education in the United States and abroad has been largely supported by private foundations (see Bacchetti \& Ehrlich, 2006; Cheit \& Lobman, 1979; Curti \& Nash, 1965; Hollis, 1938; Sears, 1990). When it comes to funding innovative research around the world, U.S. foundations do have a strong track record. From the professionalisation of public health and the spread of Western medicine in many regions of the world to strengthening the non-governmental organisation (NGO) sector and many global research institutions, examples abound. Moreover, U.S. foundations' interest in higher education is far from waning and has increased steadily as the Foundation Center's data demonstrates. The total dollar value of grants made in this field is staggering: from 2003 to 2018, U.S. foundations made 1,075,821 grants to higher education for a total of USD 91.8 billion. ${ }^{1}$

As U.S. foundations turn their attention to problems that cross borders and are linked to globalisation processes, assessing their international funding trends and influence over niche sectors such as higher education development in the Global South has become critical. In general, researchers point to the liberty that foundations have in comparison to other organisations, governments or agencies such as the World Bank, the United Nations or the United States Agency for International Development (USAID) (see Arnove, 1980; Berman, 1983; Brison, 2005; Cheit \& Lobman, 1979). Unlike governmental or multinational organisations, in the context of U.S. civil society, foundations have several distinct advantages. They are independent. They are not under pressure for short-term results. They can

\footnotetext{
1 Grants made in support of higher education, starting in the year 2006 to present (Foundation Center, n.d.).
} 
take risks. They have accumulated sensitivity and sophistication to address certain problems. And, one may argue, they have fewer historical issues to deal with than for instance, a former colonial power's development agency would have in most developing countries.

Today, many U.S. private foundations actively invest in Africa. A large share of their investments is devoted to the education sector and, particularly, to higher education institutions. Private foundations are the top grant-making contributors to higher education on the continent (e.g., the Ford Foundation, the Rockefeller Foundation and Carnegie Corporation of New York). ${ }^{2}$ Corporate foundations are the second largest type. ${ }^{3}$ These foundations are usually started by a company with a single gift that then becomes an endowment. These foundations' missions are usually aligned with the companies' own strategies (e.g., The Bristol-Myers Squibb Foundation and the Coca-Cola Foundation). Other types of philanthropies include community foundations, operating foundations and public charities. They conduct grant-making activities that often, but not always, benefit local charities and charitable community projects. These foundations may make grants, but the grant amount awarded generally is small relative to the funds used for the foundation's own programmes. Examples include the Silicon Valley Community Foundation, the New York Community Trust in New York, Open Doors International and the Oprah Winfrey Leadership Academy Foundation.

This chapter seeks to offer a nuanced analysis of U.S. foundations committed to strengthening capacity in higher education in Africa. The role of local universities in Africa's development has been a subject of debate post the independence era of the 1960s that continues today as scholars and many African governments search for ways in which to ensure that local universities contribute to Africa's development. The debate takes place in the absence of a clearly articulated framework of what should constitute Africa's development plan. ${ }^{4}$ Donor agencies have also played a role in tracing the path of development for universities, steering, directing and supporting priorities that they set for the sector. In the last two decades, donor agencies have become actively involved in setting the agenda for development in which African universities define their missions and align their priorities in order to receive funding from these agencies.

The chapter looks at the conditions under which foundations' efforts have been successful in achieving their intent in higher education devel-

\footnotetext{
2 According to the Foundation Center (n.d.).

According to the Foundation Center (n.d.).

4 In this chapter, we refer to Africa in a more generic way acknowledging the diversity that exists among the states on the continent.
} 
opment in nine African nations. It examines the dynamic and complex relationship between foundations and universities within the context of international development. The focus is on the collaboration of seven major foundations which joined forces to form the Partnership for Higher Education in Africa, hereafter referred to as the Partnership or PHEA interchangeably. In the period between 2000 and 2010, the Partnership provided funding to higher education institutions in nine African nations: Ghana, Kenya, Nigeria, Mozambique, South Africa, Tanzania, Uganda, Madagascar and Egypt. In addition, it supported regional and sub-regional organisations as well as consortia that furthered the development of higher education in Africa - the Internet Bandwidth Consortium presented below serves as a case study for this chapter.

The foundations involved were the Carnegie Corporation of New York, the Ford Foundation, the John D. and Catherine T. MacArthur Foundation, the Rockefeller Foundation, the William and Flora Hewlett Foundation, the Andrew W. Mellon Foundation and the Kresge Foundation. These foundations had two clear goals. As clearly stated on the Partnership's website (Partnership for Higher Education [PHEA], 2010b), the first was to advocate for the 'indispensable contribution of higher education to social and economic development' (para. 1) in Africa. The second goal was to accelerate the 'processes of comprehensive modernization and strengthening of universities in selected countries' (para. 2). The scope of these goals, which none of the foundations could accomplish alone, necessitated an efficient inter-institutional collaboration. This would develop the ability to serve mutually beneficial goals and priorities.

The thousands of grants made by U.S. foundations to universities in Africa in the last two decades, along with the foundations' various partnerships to provide scale to their undertakings form an impressive array of strategies and solutions geared towards developing the field of higher education on the continent. However, do the top-down mechanisms that govern a number of relationships between U.S. foundations and African universities provide satisfactory results for both actors or benefits that are not delivered to their full potential? Can the institutional dynamic at work in this relationship provide insight on grant feasibility, sustainability or institutional change? The following sections will provide answers while presenting our theoretical framework, methodology and findings.

\section{THEORETICAL FRAMEWORK}

By looking at institutional dynamics and organisational interdependencies between the seven foundations, this study investigated the factors 
impacting collaborations. Using an institutional lens, this study explored the questions of whether those factors constrained inter-organisational collaboration among the Partnership's foundations, and if so, how. Furthermore, through its institutional lens this inquiry determined whether the foundations' alignment and collaboration showed signs of institutional convergence. This was done in order to understand how organisations operate. According to DiMaggio and Powell (1983), two types of isomorphism co-exist: competitive and institutional. These make 'organizations compete not just for resources and customers, but for political power and institutional legitimacy, for social as well as economic fitness' (p. 150). Given that a foundation partnership is in and of itself an institutional process that requires partners to unite around shared values and goals for their action, the Partnership's inter-organisational exchanges can be potentially informative about the relationship between isomorphism and collaboration.

The neo-institutionalism school of thought indicates that it is not so much individual organisations that are legitimised, but rather organisational forms, structural elements, technical procedures and rules. While the Partnership's stated objective was to aid African universities, the foundations also paid close attention to their collaboration and built an inter-organisational structure that suited their individual strategies. Analysis of primary and secondary sources, including interviews with individuals directly involved in the Partnership and data on grants made during the collaboration, helps identify various elements interfering with this collaboration. These sources assist in visualising the Partnership's technical procedures and structural elements. The results presented below might not generalise to other foundations or collaborations. However, they illustrate how a group of foundations orchestrated various processes of collaboration to maximise their impact. As a result, there were multiple relationships that informed the given foundations' engagement with the Partnership: the relationship on the ground between the foundation and a given university and the rapport among the various foundations both on the ground and in the United States.

We have used the framework of collaboration theory proposed by Wood and Gray (1991) to define collaboration as a process that 'occurs when a group of autonomous stakeholders of a problem domain engage in an interactive process, using shared rules, norms, and structures, to act or decide on issues related to that domain' (p. 146). Collaboration implies sharing processes and mechanisms; it creates terrain for institutional interdependency, compelling partners to share authority and responsibility in order to fulfil their common mission. Although scholars, such as Fleishman (2007) and Bacchetti and Ehrlich (2006), argue that foundations 
are both wary and very selective about engaging in partnerships, foundations nonetheless seem to recognise the need to collaborate with others to surmount obstacles that they could not overcome alone.

However, there is a tension between sustainable results and expectation of impact and recognition which undergirds the dynamics of interorganisational collaboration, particularly among larger foundations. In a famous essay on collaboration, Paul Brest, former president of the Hewlett Foundation, wrote that foundations can work together to generate better ideas, build broader constituencies and increase the amount of money available to achieve common goals. Reflecting on the motivations of funders, he also underlined the dangers that lie in working with others:

Some donors seem more interested in funding innovative programs with immediate visible impact than in achieving long-term, sustainable results. Some have low expectations of nonprofit organizations and treat an honorable mission as a substitute for impact. And doubtless some donors are motivated more by relationships and recognition than by achieving results. More fundamentally, personal philanthropy may sometimes be so profoundly emotional as to be invulnerable to rational analysis. (Brest, 2006, p. xv)

As Brest indicates, the relationship between expectation and recognition is not always harmonious and often finds its disharmony at the human level. This is an important aspect of philanthropy, which the present study took into consideration.

Moreover, by looking at institutional dynamics and organisational interdependencies among the seven foundations, this study investigated the factors influencing legitimation in the Partnership's collaboration. The Partnership's collaborative dynamics are examined here through an institutional lens to explore the connections between collaboration and organisational legitimacy. It also examines if and how these factors constrained inter-organisational collaboration among the Partnership's foundations. Additionally, it seeks to understand the way in which private foundations operate.

This chapter argues that in order to build a strong case for higher education in Africa, the Partnership's foundations had to deploy collaboration to reinforce their status as convincing advocates. In a partnership, foundations can bring intellectual and reputational capital as well as dollars to the table. Since foundations are essentially investors, the form of collaboration seen most regularly is the aggregation of funds with other foundations, governmental institutions or grassroots organisations. Thus, the Partnership's image was intricately tied to the foundations' reputations as credible players among international and human development actors. The results produced by the Partnership generated bonus points for foundations in return. 


\section{METHODS AND DATA COLLECTION}

This study builds on previous work by Jaumont (2014, 2016a). The data presented here draws from a number of primary and secondary sources 5 including: documents (e.g., foundations' annual reports, charters and bylaws; publications from the Foundation Center); archives of the PHEA and the individual foundations belonging to the PHEA; websites (e.g., of the individual foundations, The Foundation Center); online databases (e.g., PHEA, The Foundation Center) and interviews. Twenty-one interviews were conducted in person between May 2011 to May 2012. Interviewees ${ }^{6}$ included PHEA-member foundations' programme officers, advisors and executive officers as well as a reporter. Over 120 transcripts of interviews ${ }^{7}$ of African university leaders, grant administrators, faculty and students, available from the Partnership's archives, supplemented these in-person interviews.

\section{RESULTS AND FINDINGS}

\section{Grant Distribution}

To capture the conditions of grant distribution that governed these foundations, our study reveals that U.S. foundations made 13,565 grants to Africa between 2003 and 2013 for a total of nearly USD 4 billion. ${ }^{8}$ More specifically, between 2000 and 2010 the PHEA, which included seven foundations - Carnegie, Ford, MacArthur, Rockefeller, Hewlett, Mellon and Kresge- provided USD 440 million in funding to higher education institutions in nine African countries (Grant Lewis, Friedman $\&$ Schoneboom, 2010). Figure 7.1 illustrates how each foundation contributed to this total.

Not all recipient organisations were based in Africa, since many U.S. foundations often worked with institutions of research or expertise located in developed or developing countries or with intermediary organisations. This was especially true of conflict zones or areas where foundations tended to have no previous contacts. The U.S. foundations also had a general tendency to make grants to institutions in English-speaking countries (Jaumont \& Klempay, 2015). The findings also suggest that U.S.

\footnotetext{
5 A detailed listing of primary and secondary sources is available on pages 299 to 300 of Jaumont (2014).

6 A listing of interviewees is available in Appendix A of Jaumont (2014).

7 A listing of countries, universities and roles of those interviewed can be found in Appendix C of Jaumont (2014).

8 Data retrieved from www.foundation-partnership.org.
} 


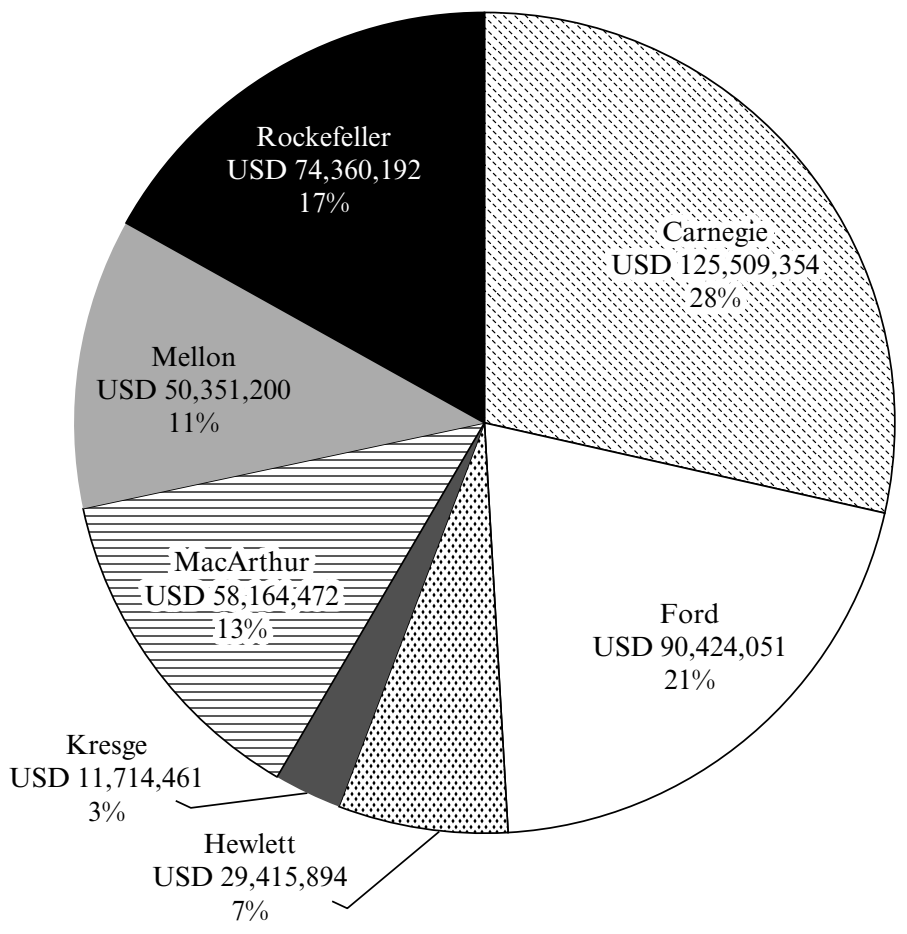

Grants Total $=$ USD 439,939,624

Source: Data retrieved from PHEA (2010a).

Figure 7.1 Total contribution and proportion of grants made by each foundation in the Partnership for Higher Education in Africa

foundations applied a geopolitical strategy of investment and maximisation along former colonial lines, in particular former British colonies, although U.S. foundations' geopolitical agendas might not be formulated with specific post-colonial considerations. However, the geographic distribution of these funds for Africa was significantly oriented towards Kenya, South Africa and Nigeria. Out of fifty-three nations on the continent, these three countries received 50 per cent of the total funding granted by U.S. foundations (Jaumont, 2016b, 2018).

The foundations joined forces to support the capacity building of universities and the field of higher education in Africa, which they saw as crucial for the development of the continent. At the time of PHEA's establishment, African higher education was less of a priority as the focus 
was frequently on primary education (Varghese, 2010). This was a result of the World Bank policies on development based on studies that claimed that there were higher rates of return for governments if they invested in basic education instead of higher education. ${ }^{9}$ Thus, PHEA was formed to change this view. It successfully raised USD 450 million over 10 years to build core capacity in universities and support special initiatives to advance higher education on the African continent (see Parker, 2010 and Grant Lewis et al., 2010). However, the Partnership's direct influence on higher education in Africa was evident as the foundations' support served the entire academic community and as many projects involved scholars and researchers across the continent and in other parts of the world. Grant Lewis et al. (2010) wrote:

The PHEA focused support in nine African countries.. . . These countries have a combined population of 459 million. In a continent with a tertiary education enrollment ratio of only $3 \%$, the PHEA has, directly and indirectly, improved conditions for 4.1 million African students enrolled at 379 universities and colleges. (p.v)

PHEA's investments led to the successful support of research initiatives across the continent and strengthened pan-African organisations such as the Association of African Universities and the Council for the Development of Social Science Research (Grant Lewis et al., 2010). More importantly, it pushed foundations to give more, as this quote from Kole Shettima, programme director of The John D. and Catherine T. MacArthur Foundation Nigeria office, explained:

The consortium, at first, was designed as I saw it to have two purposes. First to demonstrate to Africa that American foundations were really eager to be supportive. That we felt if we did it one at a time we wouldn't have the same psychological impact... . The other impact was through a kind of competition to set a total amount of money that would be assured.. . . That would in some sense prod the individual foundations to push as hard as they could in their African support. (cited in Jaumont, 2014, p. 112)

\section{Finding the Right Funder Engagement Level}

When applied to philanthropic endeavours, partnerships between private foundations are formed from time to time to tackle problems of scale on specific issues such as disease, poverty and the environment. Partnerships

9 These studies are based on Psacharopoulos (1973). The World Bank has changed its policies since the publication of later studies in 2002 (see World Bank, 2002). 


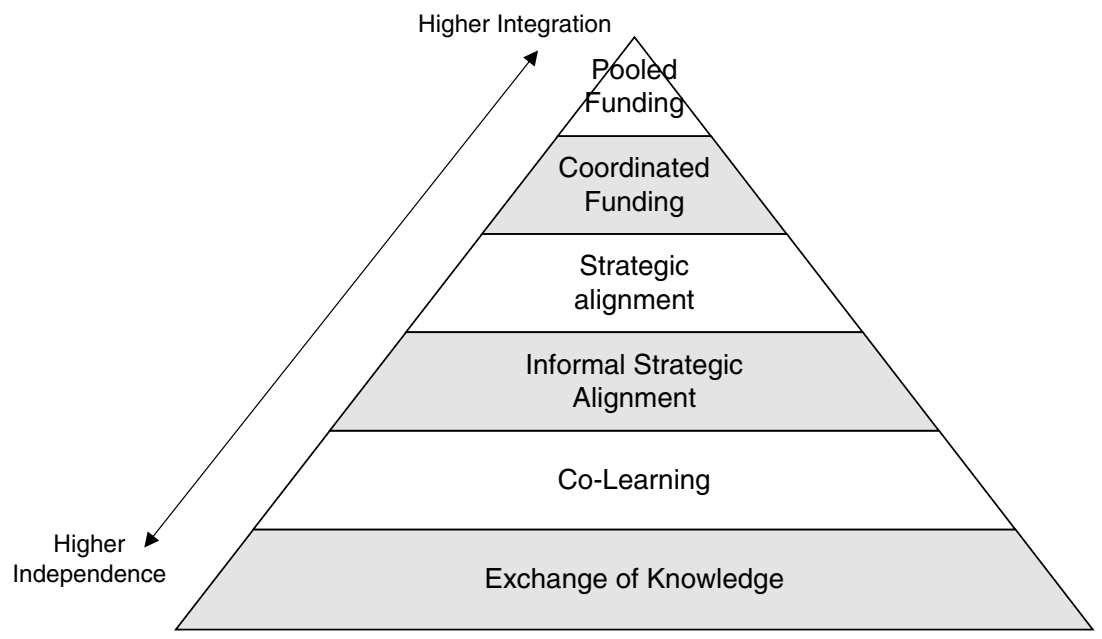

Source: Developed from work of the Foundation Center (www.foundationcenter.org), The Philanthropy Initiative (2009), and Rockefeller Philanthropy Advisors (www.rockpa.org).

\section{Figure 7.2 The spectrum of funder engagement}

evolve from mutual respect, the pairing of complementary strengths and collaborative planning and decision making. They evolve through work to achieve mutually shared goals and priorities in such areas as improvements in community and social development, environmental management, governance, health, education and private sector development.

Our literature review indicated that there are many types of partnerships and possibilities for collaborative engagement, spanning from a mere exchange of ideas and co-learning to more hybrid and organised structures such as strategic alignments, targeted collaborative funding or the creation of a separate pooled fund. In Figure 7.2, the spectrum of collaborative engagement illustrates some of the various models that are used by foundations.

The Partnership offered an interesting case of formal strategic alignment for foundations. The alignment allowed greater flexibility and control for the foundations while ensuring their full commitment. The Partnership was not a separate entity with its own charter, identity, pooled funds and grant-making programmes. Instead, as Raoul Davion, programme officer of The John D. and Catherine T. MacArthur Foundation, discussed, it was initially an informal relationship that grew out of discussions between the presidents of the four founding foundations and several senior staff: 
The design and structure [of the PHEA] was a semi-formal collaboration amongst the four foundations where the initiative really grew out of discussions among the foundation presidents, the presidents of the four founding foundations and staff was then asked to operationalize this idea of working together in support of higher education. It grew out of shared recognition of commitment and interest in the field of higher education among the foundations. And, in that sense, it was launched before it was designed, in terms of how it actually operates. (personal communication, 12 July 2011)

The Partnership eventually grew into a more elaborate structure that sought to go beyond the mere exchange of information and collaborative learning. It was formalised by an official agreement signed in 2000 by the initial four foundation presidents who initiated the project. Figure 7.3 depicts the strategic alignment in its final stage circa 2008.

The objective of this strategic alignment was to ensure greater coordination, better decision making and a separation of individual and collective boundaries. Over a decade, the Partnership's foundations interacted with 296 grantees, including universities, research centres and academic networks, among many others. The dynamics involved were rich with multiple trans-organisational exchanges between foundations, between the Partnership's secretariat and its committees, between foundations and their grantees and between the Partnership and the grantees. The Partnership's dynamics are reflected by this statement from Kole Shettima, programme director of The John D. and Catherine T. MacArthur Foundation Nigeria office:

We learned some things that we did not know before, working with other organizations in terms of even their own process of grant-making, their own processes of decision-making. We learned a lot about that. We appreciated that motivations are different; the way people do some things are different from others. It is not a question of which one is better, but it is a question of, yes, we are all different and therefore we need to appreciate and understand our differences. (personal communication, 22 June 2011)

Foundations' behaviour is best explained and understood if we take into consideration their internal character, which they inherit and develop throughout their history. As Tade Akin Aina, the programme director of the Carnegie Corporation of New York, stated:

First and foremost, the biggest problems we have is that foundations come with their cultures. . a and these traditional cultures can be as rigid as any bureaucracy. In fact, can almost be beyond, in terms of the rigidities, almost like a culture, it's almost like different princely orders. (personal communication, 26 September 2011) 


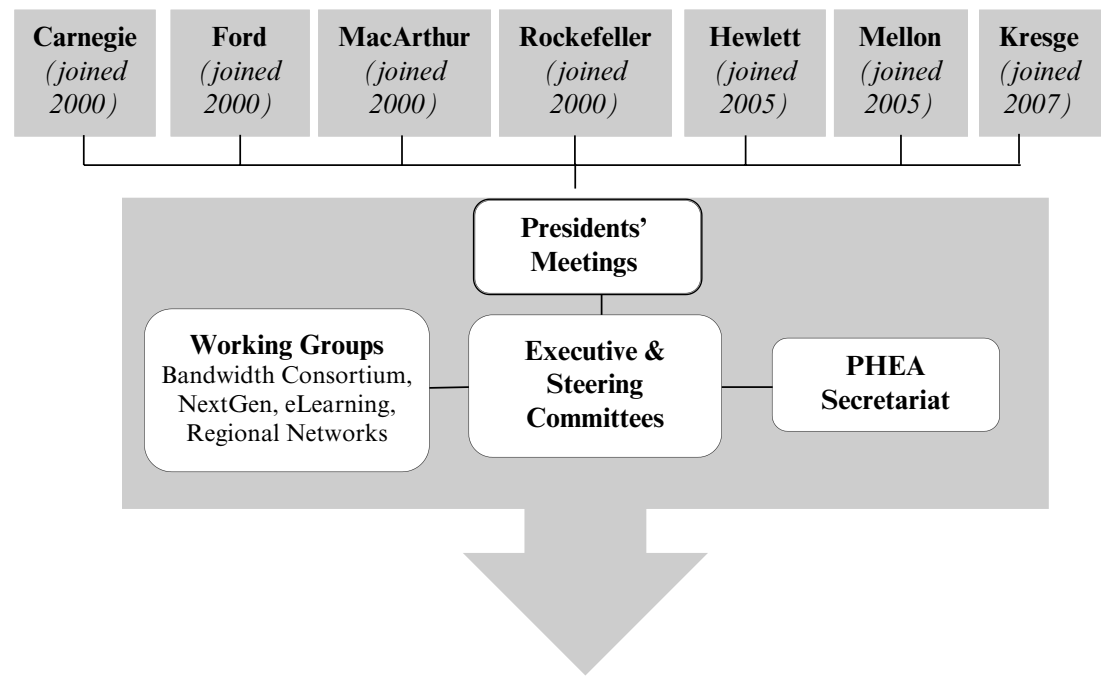

296 Grantees

\begin{tabular}{|l|l|}
\hline 67 African Universities & 39 U.S. Universities \\
\hline 16 Other Universities & 57 Education Networks \& Consortia \\
\hline 28 Research Institutes & 15 African Government Agencies \\
\hline 16 Foundations & 4 International Organisations \\
\hline 7 Museums & 2 Libraries \\
\hline 17 NGOs & 15 Parks \& Botanical Gardens \\
\hline 4 Hospitals \& Medical Centres & 4 For-Profits \\
\hline 3 Arts Centres & 1 Audit Agency \\
\hline 1 U.S. Embassy & \\
\hline
\end{tabular}

Figure 7.3 The Partnership's strategic alignment model

Rationalising the Partnership's efficiency also meant clarifying and controlling the flow of information. The strategic alignment generated multilevel communication channels orchestrated efficiently by the secretariat. In the Partnership's previous forms, the flow of information between foundations was originally an issue for overcommitted foundation staff. This is explained in greater detailed by Narciso Matos, former programme director of the Carnegie Corporation of New York: 
Sometimes very simple decisions, because it had to be consultative, were so cumbersome and they took so many emails and comments, over comments, until we reached an agreement. It was complicated. It was not from the very beginning, for example, that we had a full-time coordinator. I think that came later on where we started an office for coordination and that helped us to streamline decisions. So, I think internally, it was messy. Effective but messy. (personal communication, 9 September 2011)

A foundation's values and norms, which sometimes come directly from the donor, translate into strategies that shape the entire institution. In the case of a partnership of foundations such as PHEA, a foundation's individual tendency to follow its own priorities might not play out easily in a collaborative effort, and therefore some compromises must be reached.

Prior to the creation of PHEA, these individual foundations tended to work on a one-to-one basis with their grantees without considering working collaboratively with a group of universities or regionally (Jaumont, 2016b). As foundations act as investors, the most fundamental form of collaboration is the aggregation of funds to produce results that any single funder could not accomplish on its own. Between 2000 and 2010, Carnegie, Ford, Rockefeller and MacArthur invested an aggregate of USD 348.4 million as partners in the PHEA (Jaumont, 2014). Between 1990 and 1999, the same foundations invested a total of USD 103.7 million in African universities and research centres (Parker, 2010). Thus, by working collaboratively the foundations assembled a significant amount of funds - more than what any U.S. foundation or group of foundations had ever assembled for higher education in Africa (Jaumont, 2016b).

\section{The Challenge of Selecting Universities and the Question of Ownership}

The PHEA's rationale for selecting universities was motivated by predetermined criteria and hard-to-achieve goals. The following PHEA Core Statement from 2004 indicated the foundations' high expectations:

Selected universities and centers of intellectual inquiry will demonstrate ability to promote the free flow of ideas and enlarge the public sphere of their societies. They will exhibit a strong academic base as judged by international and local criteria, good governance, sound management, and through creative mixtures of public and private funding, financial stability... . As part of the national higher education system, they will build and transfer a repertoire of skills essential for the development of their societies and the realization of individual and national aspirations.. . . They will produce well-prepared high-level professional talent... . They will reflect a quiet revolution in institution building in Africa that can unleash the talents of the continent for the well-being of its people and those beyond its borders. (cited in Jaumont, 2014, p. 252) 
However, in their selection process PHEA foundations could not find universities that met their criteria and had to look for universities and countries 'on the move' (Parker, 2010, p. 16) in order to implement their joint strategy. The aim was to reproduce African knowledge centres by directing the foundations' financial support around building core institutional capacity in a selected group of universities. This process mainly benefited institutions which had been in contact with U.S. foundations for decades (e.g., Makerere University, University of Dar es Salaam, etc.) because there was a pre-existing shared level of trust, respect and mutual understanding (Jaumont, 2014).

The literature on African higher education highlights the importance of ownership by the local partners and mutually beneficial outcomes in the inception and implementation of new programmes. As John Ssebuwufu, former director of research and programmes at the Association of African Universities in Ghana, stated, 'The African institution must fully own the programmes, and not be left feeling that the programmes are an imposition with minimum input from their side' (cited in Fisher \& Lindow, 2008 , p. A22). This notion of programme ownership is often underestimated in international development, particularly when it is central to the relationship between a grantor and a grantee, as Narciso Matos, former programme director of the Carnegie Corporation of New York, explained:

I still recall a vice chancellor of an African university (incidentally he was the vice chancellor of one of the universities that were benefiting financially and otherwise from the partnership)... at one of the meetings. . said, 'Is it a partnership of foundations or is it a partnership between foundations and African universities? How are we involved in defining the agenda and so forth?' So that reflects that, in spite of all the efforts that we were making to be inclusive and conservative, we were not always successful in communicating that it was not [only] a partnership of four or five foundations but we wanted the voice of Africans to lead whatever we were doing. (personal communication, 9 September 2011)

If not taken into account, the lack of programme ownership can transform the foundation-university relationship into one of resistance. Consequently, ownership claims pinpoint tensions at play between a grant-receiving institution and a grant-making institution and help trace the source of resistance to institutional change. They emerge as path dependent symptoms of protest against certain models of development that belong to the past. However, they may also transpire from the actors' inability to propose a new model. For instance, African scholars regularly ask how the universities are to be made African so that they can provide African development on their own terms (Cloete et al., 2002, 2006). This vulnerable position makes them prone to influence in various directions. In this light, the weight of African universities' inheritance is still being felt as 
power struggles continue to plague African universities from both inside and outside the institutions themselves.

\section{FROM OWNERSHIP TO EQUAL PARTNERSHIPS}

The PHEA's signature initiative, the Internet Bandwidth Consortium, provides valuable insight into the potential of equal partnership between foundations and universities. Suggested by the local partners, the initiative sought to provide internet bandwidth at affordable prices to African universities. Given the complexity and scale of the problem, no individual foundation, even with large enough funding, could solve this issue alone.

With co-funding from the PHEA, universities in several Sub-Saharan countries formed a consortium to purchase a six-fold increase in bandwidth and share internet capacity at lower rates - an 'important first step towards parity in the online world', as stated in PHEA's report African Universities: Stories of change (2005, p. 3). Initially, the bandwidth initiative allowed several universities to share 93,000 kilobits per second (kbps) of internet bandwidth each month, paying an average cost of $\$ 2.33$ per kbps per month. This was especially significant considering that most African universities at the time paid an average of $\$ 7.30$ per kbps per month. A few years prior to this initiative, the total bandwidth available for an entire university was only $12,000 \mathrm{kbps}$ per month, which made research and access for all faculty and students impossible (Bandwidth Task Force Secretariat, 2003). Thanks to this collaboration, the University of Ibadan, for instance, was able to move from having only 25 dial-up links to the internet to a campus-wide system of 1,000 networked computers using both wired and wireless technologies (Bandwidth Task Force Secretariat, 2003).

The Bandwidth Consortium led both PHEA's foundations and local universities to set a common agenda for tackling a problem plaguing higher education development in Africa. Several regional organisations went on to invest in the development of this sub-sector. Thus, by transferring ownership and forming an equal partnership with this group of universities and regional partners, PHEA's foundations succeeded in solving an issue of importance to the universities, cutting down these rates and providing better and faster access while mutually benefitting from their synergy.

\section{CONCLUSIONS AND FURTHER RESEARCH}

This chapter examined the conditions under which foundations' efforts were successful in achieving their intent in higher education development 
in nine African nations. It also explored the dynamic and complex relationship between foundations and universities within the context of international development. Meeting the world's development needs is a complex and challenging task that no one institution can effectively address alone. Partnerships are essential to mobilise the world's technical and financial resources in support of development solutions. Arguably, a foundation's goal of supporting sustainable initiatives motivates its choice to fund initiatives with high leveraging potentiality. If a foundation effectively promotes a particular issue, it can succeed in activating outside funding, thus offering the promise of sustainability that it seeks.

For instance, Carnegie Corporation's focus on gender programmes, aimed at generating greater access for female students or equal career opportunities for female scholars, has become a significant priority for many other foundations. Subsequently, gender has also reached a higher rank on the agenda of most regional and multinational organisations involved in higher education in Africa. Universities now offer African women unparalleled access to learning and research opportunities, increasing the network of African experts who can contribute to the efforts of poverty reduction and address other crucial challenges.

To a lesser degree, NGOs and regional organisations, such as the New Partnership for Africa's Development or the African Union, were also influenced by foundations' funding choices. For instance, the African Union recognised the work of the foundations and added several initiatives to its agenda as a sign of greater commitment to harmonising the field of higher education in Africa and increasing the quality of educational publishing, teacher development and the revitalisation of technical and vocational education.

The nature of donor-recipient relationships, if strategically steered to a relationship of equals, is likely to have a positive impact on design, implementation and outcomes of projects. We acknowledge that huge sums of money translate to huge power. Foundations with massive funds are able to form partnerships with African universities on a different footing than those established with large individual foundations or international organisations. However, this approach, which seemingly makes it easier for a partner foundation to handle a recipient's requests, actually becomes quite restrictive as it allows foundations to impose conditions and rules for funding areas and pre-determine needs. The PHEA's foundations and universities partnering in the Bandwidth Consortium were able to set up an equal and mutually beneficial partnership that allowed them to accomplish significant work. However, most partnerships between foundations and their grantees are rarely established on mutually beneficial grounds. Such tendencies and their restrictive effect on outcomes can best be understood 
by a closer analysis of the internal and external forces at play in the relationship between foundations and universities.

Furthermore, the transfer of ownership between actors or opposition to decisions without consultation plays a decisive role in the success of a programme. Some ownership rights might not be easily transferred, and the fact that they are not indicates the role these rights will play in the success of the initiative or the durable implementation of new ideas. The benefits of ownership transfer may include improved collaboration, partnership-building, staff morale, fundraising and efficiency, as well as the sought-after inception of change, as the Bandwidth Consortium suggests. Programme ownership does not involve exclusive rights and control, as seen with the Bandwidth Consortium where grant-receiving institutions owned a small share of the funded initiative. The downside of ownership transfer may include, on the other hand, resistance, institutional dependency or failure to make any progress.

While U.S. foundations attempt to transform African universities through their granting activities, they must base their vision of change on the needs, the norms and the values of local actors. In recent years, these foundations have sought to infuse neoliberal trends in African higher education. They have done this while promoting the knowledge economy, which focuses on the production and management of knowledge and sees universities as engines for economic growth and increased competitiveness. Of course, this trend has not only affected higher education in Africa but universities across the globe. Yet, this vision for change can only happen in countries undergoing systemic public policy reform as well as in strong individual institutions that can operate within differentiated national systems of higher education, all while encouraging inter-institutional collaboration.

Higher education institutions and foundations are confronted with internal as well as external challenges due to environmental complexity. Foundations rely on their programmes' congruence with particular characteristics in the nations of the grantees' educational systems. For instance, funding to higher education in Africa is dependent on both national and global shifts in the grantor's country and on the receptiveness of African governments and institutions to the modalities of private funding. States define substantive direction and exert significant authority over educational policy. If processes of democratisation, decentralisation and economic reform are not in place to grant greater autonomy to universities, foundations' grant-making will have limited effects on outcomes in universities. African states may recognise the value of these outside players in terms of national development and poverty alleviation, but they might also see their interactions with universities as a potential threat to their 
authority. Some may even reject the use of foreign models as they might be a threat to the universities' very existence and legitimacy. Thus, the independence of a university is an important factor that contributes to its ability to attract outside funding from donors. In order to maximise the capacity for institutional change, foundations and universities must verify the presence of this central condition for a successful relationship and foster mutual understanding and ownership sharing on all initiatives undertaken jointly.

This raises several questions that call for further research. If change does not occur, to what degree has the interaction between the grantor and the grantee hampered the programme, and can this be remedied at some point? In other words, if the transfer of ownership can be made - that is, a larger share in the decision-making process can be transferred to the grantee by the grantor or more independence transferred by the state to the grantee - would that be beneficial to the success of the programme, and to what extent would that help foster the commonly desired institutional change?

It is in this context that we believe the review and comparison of privately and publicly funded programmes would yield constructive lessons for the fields of both philanthropy and development which, to a certain extent, have yet to integrate the concept of evaluation into their grantmaking activities. The lessons learned may suggest alternative ways that can foster a relationship of equals between donors and recipients through collaborative projects geared towards a common goal. There might also be lessons inherent in such studies for establishing regional cooperation as a more effective framework for development and for encouraging interinstitutional partnerships. Another dimension where such studies could make a contribution is in helping grant-makers become more efficient by focusing on the core definition of philanthropy, which in essence promotes giving not for expecting something in return but rather for empowering the grant recipient towards a more meaningful relationship.

\section{REFERENCES}

Arnove, R. F. (Ed.). (1980). Philanthropy and cultural imperialism: The foundations at home and abroad. Boston, MA: G. K. Hall.

Bacchetti, R., \& Ehrlich, T. (Eds.). (2006). Reconnecting education \& foundations, turning good intentions into educational capital. Stanford, CA: The Carnegie Foundation for The Advancement of Teaching.

Bandwidth Task Force Secretariat. (2003). Securing the linchpin: More bandwidth at lower cost: An investigation for the Partnership for Higher Education in Africa. Compiled by the University of Dar es Salaam, Dar es Salaam, Tanzania. 
Berman, E. (1983). The ideology of philanthropy: The influence of the Carnegie, the Ford, and Rockefeller Foundations on American foreign policy. Albany, NY: State University of New York Press.

Brest, P. (2006). On collaboration, or how many foundations does it take to change a light bulb? In The William and Flora Hewlett Foundation annual report 2005 (pp. ix-xvii). Menlo Park, CA: The William and Flora Hewlett Foundation.

Brison, J. D. (2005). Rockefeller, Carnegie, and Canada: American philanthropy and the arts and letters in Canada. Montreal, QC: McGill-Queen's University Press.

Cheit, E. F., \& Lobman, T. E. (1979). Foundations and higher education: Grant making from golden years through steady state. Berkeley, CA: Carnegie Council on Policy Studies in Higher Education.

Cloete, N., Maassen, P., Fehnel, D., Moja, T., Perold, H., \& Gibbon, P. (Eds.). (2002). Higher education policy, institutions and globalisation: New dynamics in South Africa after 1994. Dordrecht, the Netherlands: Kluwer Academic Publishers.

Cloete, N., Maassen, P., Fehnel, R., Moja, T., Gibbon, T., \& Perold, H. (Eds.). (2006). Transformation in higher education: Global pressures and local realities. Dordrecht, the Netherlands, Springer.

Curti, M., \& Nash, R. (1965). Philanthropy in the shaping of American higher education. New Brunswick, NJ: Rutgers University Press.

DiMaggio, P. J., \& Powell, W. (1983). The iron cage revisited: Institutional isomorphism and collective rationality in organizational fields. American Sociological Review, 48(2), 147-160.

Fisher, K., \& Lindow, M. (2008, July 18). Africa attracts renewed attention from American universities. The Chronicle of Higher Education, 54(45), A21-A23.

Fleishman, J. (2007). The foundation: A great American secret: How private wealth is changing the world. New York, NY: PublicAffairs.

Foundation Center. (n.d.). Foundation directory online. Retrieved December 2, 2018, from http://foundationcenter.org/products/foundation-directory-online

Grant Lewis, S., Friedman, J., \& Schoneboom, J. (2010). Accomplishments of the Partnership for Higher Education in Africa, 2000-2010: Report on a decade of collaborative foundation investment. New York, NY: New York University.

Hollis, E. V. (1938). Philanthropic foundations and higher education. New York, NY: Columbia University Press.

Jaumont, F. (2014). Strategic philanthropy, organizational legitimacy, and the development of higher education in Africa: The Partnership for Higher Education in Africa (2000-2010) (Doctoral dissertation). Retrieved from ProQuest (3613476).

Jaumont, F. (2016a). Dynamics of collaboration between U.S. foundations and African universities. In H. Alphin, J. Lavine, S. Stark, \& A. Hocker (Eds.), Facilitating higher education growth through fundraising and philanthropy (pp. 167-185). Hershey, PA: IGI Global.

Jaumont, F. (2016b). Unequal Partners: U.S. Foundations and higher education development in Africa. New York, NY: Palgrave-MacMillan.

Jaumont, F. (2018). Partenaires inégaux. Fondations américaines et universités en Afrique [Unequal Partners: U.S. Foundations and higher education development in Africa]. Paris, France: Editions de la Maison des sciences de l'homme.

Jaumont, F., \& Klempay J. (2015). Measuring the influence of language on grantmaking by U.S. foundations in Africa. Reconsidering Development, 4(1), 51-65.

Parker, S. (2010, September). Lessons from a ten-year funder collaborative: A case 
study of the Partnership for Higher Education in Africa. St. Johnsbury, VT: Clear Thinking Communications.

Partnership for Higher Education in Africa (PHEA). (2005). African universities: Stories of change. New York, NY: Author.

Partnership for Higher Education in Africa (PHEA). (2010a). Grants database. 12 October. Retrieved June 19, 2019, from http://www.foundation-partnership.org/ index.php?id=2

Partnership for Higher Education (PHEA). (2010b, October 12). What is the partnership? Retrieved June 19, 2019, from http://www.foundation-partnership. org/index.php?id=9

The Philanthropy Initiative. (2009). Donor collaboration: Power in numbers. Boston, MA: Author.

Psacharopoulos, G. (1973). Returns to education: An international comparison. Amsterdam, the Netherlands: Elsevier.

Sears, J. B. (1990). Philanthropy in the history of American higher education. New Brunswick, NJ: Transaction Publishers.

Varghese, N. V. (2010). Higher education aid: Setting priorities and improving effectiveness. Journal of International Cooperation in Education, 13(2), 173-187.

Wood, D. J., \& Gray, B. (1991). Toward a comprehensive theory of collaboration. The Journal of Applied Behavioral Science, 27(2), 139-162.

World Bank. (2002). Constructing knowledge societies: New challenges for tertiary education. Washington, DC: Author. 